\title{
Patient-reported outcomes measured with and without dizziness associated with non-specific chronic neck pain: implications for primary care
}

\author{
Raúl Ferrer Peña ${ }^{\text {Corresp., }}{ }^{1}$, Gonzalo Vicente-de-Frutos ${ }^{1}$, Diego Flandez-Santos ${ }^{1}$, Carlos Martín-Gómez ${ }^{1}$, Carolina \\ Roncero-Jorge $^{2}$, César Calvo-Lobo ${ }^{\text {Corresp. } 3}$ \\ ${ }^{1}$ Centro Superios de Estudios Universitarios La Salle Madrid, Madrid, Madrid, Spain \\ 2 Hospital Universitario del Sureste, Arganda del Rey, Madrid, Spain \\ 3 Institute of Biomedicine (IBIOMED), Nursing and Physical Therapy Department, Universidad de León, Ponferrada, León, España \\ Corresponding Authors: Raúl Ferrer Peña, César Calvo-Lobo \\ Email address: raul.ferrer@lasallecampus.es, cecalvo19@hotmail.com
}

Background: The aim of this study was to compare health-related quality of life (HRQoL) and disability and fear of movement in patients with non-specific chronic neck pain (NSCNP) associated with dizziness with respect to patients with isolated NSCNP in primary care settings.

Methods: A cross-sectional study was carried out in a primary care center. A total of 120 patients were divided into two groups and analyzed in this study. One group of patients reported dizziness combined with NSCNP $(n=60)$, and the other reported no dizziness with their NSCNP $(n=60)$. Patient-reported outcome measurements were HRQoL (primary outcome) and disability and kinesiophobia (secondary outcomes) assessed by the EuroQoL Five Dimensions and Five Levels (EQ-5D-5L), neck disability index (NDI) and Tampa Scale of Kinesiophobia (TSK-11), respectively.

Results: Statistically significant differences $(\mathrm{P}<0.05)$ for a $95 \%$ confidence interval $(\mathrm{Cl})$ with a large effect size (Cohen $d$ ) were found between both groups with greater values of disability (mean difference $=6.30$ points; $95 \% \mathrm{Cl}=3.84-8.75 ; d=0.94$ ) and kinesiophobia (mean difference $=8.36$ points; $95 \% \mathrm{Cl}$ $=6.07-10.65 ; d=1.33$ ), and an impairment of HRQoL (mean difference $=16.16$ points; $95 \% \mathrm{Cl}=11.09$ - 21.23; $d=1.16$ ), for patients with NSCNP associated with dizziness with respect to patients with isolated NSCNP.

Conclusions: Patients with NSCNP in conjunction with dizziness present higher HRQoL impairment and higher disability and kinesiophobia compared to patients with isolated NSCNP. 


\section{Patient-reported outcomes measured with and without}

\section{dizziness associated with non-specific chronic neck pain:}

\section{implications for primary care}

1 Running title: Dizziness \& neck pain primary-care

2 Raúl Ferrer-Peña ${ }^{1,2,3}$, Gonzalo Vicente-de-Frutos ${ }^{4,5}$, Diego Flandez-Santos ${ }^{4,5,6}$, Carlos Martín-

3 Gómez ${ }^{1}$, Carolina Roncero-Jorge, ${ }^{7}$ César Calvo-Lobo ${ }^{8}$.

1 Physical Therapy Department, Centro Superior de Estudios Universitarios La Salle, Universidad Autónoma de Madrid, Spain

2 Motion in Brains Research Group, Instituto de Neurociencias y Ciencias del Movimiento (INCIMOV), Centro Superior de Estudios Universitarios La Salle, Universidad Autónoma de Madrid, Spain

3 Centro de Salud Entrevías, Gerencia de Atención Primaria, Fundación para la Investigación e Innovación Biomédica en Atención Primaria de la Comunidad de Madrid (FIIBAP), Servicio Madrileño de Salud, Madrid, Spain.

4 Clinica Fisioterapia Fisiolab, Madrid, Spain.

5 Unidad de Patología de Hombro y Codo de Madrid, Madrid, Spain.

6 Instituto de Rehabilitación Funcional (IRF). Centro Superior de Estudios Universitarios La Salle, Universidad Autónoma de Madrid, Spain 
7 Servicio de Enfermería en Hospitalización Medica. Hospital Universitario del Sureste, Arganda del Rey, Madrid, España.

48 Nursing and Physical Therapy Department, Institute of Biomedicine (IBIOMED), Universidad

5 de León, Ponferrada, León, Spain.

\section{Corresponding Author:}

6 Cesar Calvo Lobo, PhD, Msc, PT. Nursing and Physical Therapy Department, Institute of

7 Biomedicine (IBIOMED), Universidad de León. Address: Av. Astorga, s/n, 24401 Ponferrada,

8 León, Spain. Telephone: +0034 987442053, Email: cecalvo19@hotmail.com

10 AUTHOR DISCLOSURES

11 Acknowledgment of any presentation of this material:

12 No presentation of this material before.

13 Acknowledgment of financial support, including grant numbers:

14 No financial support.

15 Explanation of any conflicts of interest:

16 No conflicts of interest.

18 Words count: 2409

19 Tables count: 4

20 Figures count: 0 


\title{
Patient-reported outcomes measured with and without
}

\section{dizziness associated with non-specific chronic neck pain:}

\section{implications for primary care}

22 Running title: Dizziness \& neck pain primary care

23

24

25

26

27

\begin{abstract}
Background: The aim of this study was to compare health-related quality of life (HRQoL) and disability and fear of movement in patients with non-specific chronic neck pain (NSCNP) associated with dizziness with respect to patients with isolated NSCNP in primary care settings.
\end{abstract}

Methods: A cross-sectional study was carried out in a primary care center. A total of 120 patients were divided into two groups and analyzed in this study. One group of patients reported dizziness combined with NSCNP ( $n=60)$, and the other reported no dizziness with their NSCNP $(n=60)$. Patient-reported outcome measurements were HRQoL (primary outcome) and disability and kinesiophobia (secondary outcomes) assessed by the EuroQoL Five Dimensions and Five Levels (EQ-5D-5L), neck disability index (NDI) and Tampa Scale of Kinesiophobia (TSK-11), respectively.

Results: Statistically significant differences $(\mathrm{P}<0.05)$ for a $95 \%$ confidence interval $(\mathrm{CI})$ with a large effect size (Cohen $d)$ were found between both groups with greater values of disability (mean difference $=$ 6.30 points; $95 \% \mathrm{CI}=3.84-8.75 ; d=0.94$ ) and kinesiophobia (mean difference $=8.36$ points; $95 \%$ $\mathrm{CI}=6.07-10.65 ; d=1.33)$, and an impairment of HRQoL (mean difference $=16.16$ points; $95 \% \mathrm{CI}=$ $11.09-21.23 ; d=1.16$ ), for patients with NSCNP associated with dizziness with respect to patients with isolated NSCNP. 
40 Conclusions: Patients with NSCNP in conjunction with dizziness present higher HRQoL impairment and

41 higher disability and kinesiophobia compared to patients with isolated NSCNP.

42 Keywords: Disability; Dizziness; Neck Pain; Primary care; Quality of Life.

\section{Introduction}

Worldwide, non-specific chronic neck pain (NSCNP) is defined as chronic pain (at least three months in duration) in the neck region without a specific origin with or without referred pain to upper limbs. This non-specific origin may be secondary to the difficulties in establishing an accurate pathological diagnosis, the role of imaging tests cannot explain the symptoms as well as its multidimensional nature (Huisstede et al., 2007; Matsumoto et al., 2010). This condition is considered a common musculoskeletal condition and has a substantial impacts on patientreported outcome measurements such as health-related quality of life (HRQoL) and functionality (Hoy et al., 2014; Vos et al., 2016). Indeed, 22\% of primary care patients reported persistent pain and are more likely to suffer from activity limitations and unfavorable health perceptions (Gureje et al., 1998).

Dizziness is considered a common and challenging condition that is observed in primary care settings and has often been reported as one of the major symptoms associated with NSCNP (Wipperman, 2014; Iglebekk, Tjell \& Borenstein, 2017). In addition, patients with NSCNP may suffer from cervicogenic dizziness with a frequency similar to patients who suffer from cervical spine degeneration and whiplash (Wrisley et al., 2000; Treleaven, Jull \& Sterling, 2003; Kristjansson \& Treleaven, 2009; Hain, 2015). Cervicogenic dizziness is a common condition that seems to lead to complications such as instability and misbalance combined with disability and 
62 HRQoL impairment (Wrisley et al., 2000; Reid \& Rivett, 2005; Weidt et al., 2014; Grande-

63 Alonso et al., 2018a).

64 Cervicogenic dizziness may be defined as a non-specific anomalous spatial sensation generated

65 by anomalous afferences from the cervical spine. Indeed, it is known that cervicogenic dizziness

66 may be modified secondary to visual, vestibular, and somatosensory system inputs, which

67 control body balance and stability and whose alterations may produce neck pain, headache,

68 and/or muscle stiffness (Minguez-Zuazo et al., 2016). Nevertheless, a differential diagnosis

69 should be considered between cervicogenic dizziness (Devaraja, 2018) and several clinical

70 entities dealing with specific vestibular alterations such as whiplash and associated disorders

71 (Treleaven et al., 2016) or Benign Paroxysmal Positional Vertigo (BVVP) (Argaet, Bradshaw \&

72 Welgampola, 2019).

73 Thus, patients who suffer from NSCNP-associated cervicogenic dizziness seem to acquire

74 maladaptive beliefs such as fear of movement, perceived disability, and postural motor control 75 alterations (Dickin, 2010; Alahmari et al., 2014; Minguez-Zuazo et al., 2016; Grande-Alonso et 76 al., 2018a). It is known that patients with NSCNP (Hoy et al., 2014; Vos et al., 2016) and 77 patients with dizziness (Wrisley et al., 2000; Weidt et al., 2014) present an impaired HRQoL and 78 are some of the most frequently seen patients among primary care patients (Gureje et al., 1998; 79 Wipperman, 2014). Nevertheless, the effects of dizziness added to NSCNP have not yet been 80 addressed in primary care patients regarding patient-reported outcome measurements such as

81 HRQoL, disability, and kinesiophobia. Indeed, dizziness may impair both physical and mental

82 HRQoL domains due to its association with clinical symptoms and psychosocial factors

83 remaining as a challenge to orthopaedic and vestibular rehabilitation specialists (Wrisley et al.,

84 2000; Weidt et al., 2014). We hypothesized that patients with NSCNP in conjunction with 
85 dizziness would present higher HRQoL impairment in addition to higher levels of disability and

86 kinesiophobia. Therefore, the main aim of this study was to compare HRQoL as the primary

87 outcome and disability and fear of movement as secondary outcomes in patients with NSCNP

88 associated with dizziness with respect to patients with isolated NSCNP in primary care settings.

89 In addition, the secondary objective was to correlate HRQoL, disability and fear of movement

90 outcome measurements for both patients with NSCNP associated with dizziness and patients

91 with isolated NSCNP.

92

93 Methods

94 Study Design

95 A descriptive, cross-sectional design using non-probability convenience sampling was done. All 96 participants were recruited from September 2017 until February 2018. Patients must have been

97 diagnosed as NSCNP by their referring general practitioner from two primary healthcare centers

98 in Madrid (Spain) and also had been referred to the Physical Therapy Unit. All subjects gave

99 their written informed consent. This study was approved by the Southeast Local Research

100 Committee of the Primary Health Care Management (Code 07/17). The study reporting

101 followed the "Strengthening the Reporting of Observational studies in Epidemiology"

102 (STROBE) guidelines (von Elm et al., 2007).

103

\section{Subjects}

105 The study included two groups of patients with NSCNP: (1) those who perceived dizziness

106 combined with NSCNP and (2) those who only had NSCNP. All of them were recruited with

107 frequency matching pairing methods (Setia, 2016). The selection of the sample was carried out 
108 by a physical therapist with more than 13 years of clinical experience based on the clinical record

109 and diagnoses provided by a primary care physician. Inclusion criteria for study participants

110 consisted of several parameters: (1) referred to the Primary Health Physical Therapy Unit after

111 complaining of neck pain; (2) having pain for at least three months or longer; (3) a pain intensity

112 greater than $30 \mathrm{~mm}$ on a Visual Analogue Scale (VAS); 4) between 18 and 75 years old; and 5)

113 (specific to study group) record of dizziness associated with their neck pain in the assessment

114 date. The exclusion criteria consisted of several parameters: (1) patients who presented systemic

115 illness (such as rheumatoid arthritis, cancer, and/or fibromyalgia); (2) history of cervical region

116 traumas or surgeries; (3) presence of diagnosed radiculopathies or cervical myelopathies; or (4)

117 presently undergoing treatment or having received any type of treatment during the last three

118 months.

119

120 Data collection

121 A sociodemographic questionnaire asking about gender, age, height, weight, body mass index

122 (BMI), civil state, education level, chronicity time, pain intensity, and the actual presence of

123 perceived dizziness was administered to all study participants. The patient-reported outcome

124 measurements were the HRQoL (primary outcome) in addition to pain intensity, disability, and

125 kinesiophobia (secondary outcomes).

126

127 Primary Outcome

128 Health Related Quality of Life

129 HRQoL was measured using the Spanish version of the EuroQoL Five Dimensions and Five

130 Levels (EQ-5D-5L). This questionnaire has been widely used in the literature to report perceived 
131 HRQoL for many health-related conditions (Herdman et al., 2011; Obradovic, Lal \& Liedgens,

132 2013; Oppe et al., 2014). The instrument consists of two elements. The first one is a 5-item

133 questionnaire with one item for each assessed domain (mobility, self-care, usual activities,

$134 \mathrm{pain/discomfort,} \mathrm{and} \mathrm{anxiety/depression)} \mathrm{and} \mathrm{five} \mathrm{levels} \mathrm{on} \mathrm{each} \mathrm{domain} \mathrm{(no,} \mathrm{slight,} \mathrm{moderate,}$

135 severe, or extreme problems). Patients were asked to fill out only one level for each domain (1 to

136 5). The digits on each domain were then combined into a 5-digit number ranging from 11,111 to

13755,555 . In order to interpret the results on the EQ-5D-5L, we used the EuroQoL Index (EQ-

138 Index). This approach compares the values in the five dimensions with 3125 different hypothetic

139 health states adjusted by country population with the " 0 " value assigned to death and " 1 " as the

140 perfect health status. Values less than 0 are considered in the index, and those statuses are

141 interpreted as "worse than being dead". The minimum clinically important difference (MCID)

142 for the EQ-5D was estimated to be a mean of 0.18 points on a scale ranging from 0.03 to 0.52

143 points (Coretti, Ruggeri \& McNamee, 2014).

144 Also, the EQ-5D-5L results can be interpreted according to the HRQoL Sum Score, which is a

145 severity index obtained from the summation of the levels in each of the instrument's dimension,

146 then subtracting five points, and multiplying the result by five. It results in a new scale ranging

147 from 0 to 100 points on which more points indicate more severity. The other side of the

148 instrument consists of a vertical $20 \mathrm{~cm} E Q-V A S$ on which subjects are asked to self-rate their

149 health, from 0 "The worst health you can imagine" to 100 "The best health you can imagine".

150 Finally, psychometric properties of the EQ-5D-5L showed a minimal floor and ceiling effect

$151(<3 \%)$, a Cronbach's $\alpha$ of 0.86 and a strong correlation from 0.688 to 0.782 with pain and

152 function scores (Bilbao et al., 2018). 


\section{Secondary Outcomes}

\section{Pain Intensity}

156 The average pain intensity from the last seven days was measured using a visual analogue scale

157 (VAS). This scale consists of one horizontal $100 \mathrm{~mm}$ line on which the patients must indicate

158 their pain intensity. At the left side of the line the text "No Pain" appears, and on the right side

159 the text "Worst possible pain" appears. This instrument was previously shown to be valid and

160 reliable for measuring pain intensity (Jensen, Karoly \& Braver, 1986; Jensen et al., 1999). The

161 VAS psychometric properties showed an intraclass correlation coefficient (ICC) of 0.97 (95\%

162 confidence interval from 0.96 to 0.98$)$ (Bijur, Silver \& Gallagher, 2001).

163 Disability

164 The neck disability index (NDI) may be considered as a validated 10-item tool with each item 165 ranked on a 6-point scale (Vernon, 2008). This questionnaire is the most commonly used tool for 166 NSCNP (Vernon, 2008; Kovacs et al., 2008; MacDermid et al., 2009) consisting of a Spanish 167 cross-cultural adapted and validated version with adequate psychometric properties, showing a 168 Cronbach $\alpha$ of 0.89 , an ICC of 0.98 and a Pearson correlation coefficient $(r)$ from 0.65 to 0.89 169 with pain scales and questionnaires (Andrade Ortega, Delgado Martínez \& Almécija Ruiz,

170 2010). Its scores may be divided into five categories: (1) $\leq 4$ points for no disability; (2) 5-14

171 points for mild disability; (3) 15-24 points for moderate disability; (4) 25-34 points for severe 172 disability; and (5) $\geq 35$ points for complete disability (Vernon, 2008; Kovacs et al., 2008; 173 MacDermid et al., 2009).

\section{Kinesiophobia}

175 The fear of movement was self-reported by means of the Spanish-validated 11-item version of

176 the Tampa Scale of Kinesiophobia (TSK), which showed good psychometric properties, with an 
177 Cronbach $\alpha$ of 0.78 and an ICC of 0.82 , for chronic back pain (Roelofs et al., 2004; Gómez-

178 Pérez, López-Martínez \& Ruiz-Párraga, 2011). Each item may be scored on a 4-point Likert-type

179 scale with the scale ranging from "strongly agree" to "strongly disagree." Total scores varied

180 from 11 to 44; higher scores indicated more fear of movement (Gómez-Pérez, López-Martínez \&

181 Ruiz-Párraga, 2011).

182

183

184

185

186

187

188

189

190

191

192

193

194

195

196

197

198

199

200

\section{Sample Size}

The sample size was estimated using $G^{*}$ Power 3.1.9.2 for Mac OS X (G*PowerC) from University of Dusseldorf, Germany) in order to determine a sufficient sample size. The sample size calculation was based on the HRQoL Sum Score (severity index) of the EQ-5D-5L as the main outcome measurement (Herdman et al., 2011; Obradovic, Lal \& Liedgens, 2013; Oppe et al., 2014), A Student's t-test with two groups based on a medium effect size $(d=0.52)$ obtained from a pilot study with 10 subjects, 5 patients reported dizziness combined with NSCNP (34.00 \pm 18.84 points $)$ and 5 patients reported no dizziness with their NSCNP $(26.00 \pm 15.17$ points $)$, was used to obtain the sample size calculation with a statistical power of $80 \%$ using an $\alpha$ error of 0.05 and two tails (Faul et al., 2007). Based on the aforementioned assumptions, we estimated a sample size of at least 120 subjects, 60 patients for each group.

96 Statistical Analysis

97 All data analyses were performed on SPSS for Mac OS X, Version 22.0 (SPSS Inc., Chicago IL) with an 95\% confidence interval (CI). Statistically significant differences were considered P-values $<$ 0.05. Descriptive statistics were generated for the sociodemographic data (such as age, BMI, chronicity time, pain intensity, and others). The Kolmogorov-Smirnoff test was performed and 
201 showed that the majority of the variables were normally distributed in the sample, so parametric

202 tests were used because of the central limit theorem for samples $>50$ subjects per group (Mouri,

203 2013; Hazut et al., 2015). Continuous variables are presented as mean and standard deviation,

204 and the categorical variables are presented as absolute numbers and relative frequency

205 (percentages).

206 A chi-squared test was used for a comparison of the other qualitative sociodemographic variables

207 and also for the five dimensions of the EQ-5D-5L comparison between groups. A Student's t-test

208 for independent samples was used to compare quantitative sociodemographic variables, the

209 HRQoL Sum Score, EQ-VAS variables, neck pain disability, and kinesiophobia between groups.

210 Effect sizes were calculated by Cohen's $d$ and divided into small effect size $(d=0.20-0.49)$,

211 medium effect size $(d=0.50-0.79)$ and large effect size $(d>0.80)$ (Kelley \& Preacher, 2012).

212 Regarding both groups, univariate correlation analyses were performed by the Pearson's

213 correlation coefficient and categorized as weak $(r=0.00-0.40)$, moderate $(r=0.41-0.69)$ or

214 strong $(r=0.70-1.00)$ correlations (Sedgwick, 2012).

215

216 Results

217 A total of 120 patients were divided into two groups and analyzed in this study. One group of

218 patients reported dizziness combined with NSCNP $(n=60)$, and the other reported no dizziness

219 with their NSCNP ( $n=60)$. Sociodemographic and descriptive data did not show any statistically

220 significant differences $(\mathrm{P}>0.05)$ between groups. Descriptive variables of both groups are

221 presented in Tables 1 and 2.

222

223 Primary outcomes 
224 The EQ-index analysis revealed a statistically significant difference between groups $(\mathrm{P}<0.001)$

225 based on the Student's t-test comparison with $0.77 \pm 0.16$ and $0.54 \pm 0.21$ (mean $\pm \mathrm{SD}$ ) for the

226 non-dizziness and dizziness groups, respectively.

227 The chi-squared test compared the individual domains and levels of the EQ-5D-5L between

228 groups and showed statistical differences $(\mathrm{P}<0.05)$ in the five domains presenting higher levels

229 for the dizziness group with respect to the non-dizziness group (Table 3).

230

\section{Secondary outcomes}

232 Regarding the Student's t-test, a statistical difference $(\mathrm{P}<0.05)$ was found between both groups

233 with respect to the quantitative variables, showing greater neck pain disability and kinesiophobia

234 values and also lower values of HRQoL variables in the dizziness group versus the non-dizziness

235 group. The results of the comparison for the other quantitative variables are presented in Table 4.

236

237 Correlation Analyses

238 The Pearson's correlation analysis revealed statistically significant positive correlations in the

239 dizziness group for the HRQoL Sum Score with the perceived disability $(\mathrm{P}<0.001 ; \mathrm{r}=0.649)$,

240 and moderate positive correlations with pain intensity and kinesiophobia. Also, the analyses

241 revealed statistically significant correlations between all analyzed variables. The results are

242 presented in Table 5.

243 Regarding the non-dizziness group, the Pearson's correlation analyses showed statistically

244 significant positive correlations between the HRQoL Sum Score and the perceived disability $(\mathrm{P}<$ $2450.001 ; \mathrm{r}=0.725)$ and negative correlations with the self-perceived health status $(\mathrm{P}<0.001 ; \mathrm{r}=$ 246 0.558). The results are presented in Table 6. 


\section{Discussion}

249 To the authors' knowledge, this is the first study that has addressed the effects of dizziness and

250 NSCNP together in primary care patients who presented an impairment in patient-reported

251 outcome measurements such as the HRQoL, disability levels, and kinesiophobia. According to

252 the mentioned neurophysiological model (Minguez-Zuazo et al., 2016; Devaraja, 2018), the

253 hypothesis of this model resides in the fact that the alteration of a sensory input, specially

254 provided by the neurophysiological pathways between the upper cervical region and the

255 subsystems that form the postural control, could cause sensations of dizziness secondary to an

256 integration incongruity between the aberrant cervical somatosensory input and the expected

257 physiological sensory patterns (Kristjansson \& Treleaven, 2009). Indeed, vestibular and

258 somatosensory systems could compensate for alterations in balance by increasing the rigidity of

259 the body, mainly in the cervical region, thus explaining the hyperactivity of the cervical

260 musculature in patients with cervicogenic dizziness (Minguez-Zuazo et al., 2016; Devaraja,

261 2018). Nevertheless, patients with NSCNP presented an alteration in cervical neuro-sensorimotor

262 control and, conversely, these patients did not present dizziness (Falla, Bilenkij \& Jull, 2004).

263 This issue may be explained by the presence of dizziness could be mediated by an amplified

264 central sensitization process (Holle et al., 2015)

265 Recently, the cervico-ocular reflex was shown to be increased in both patients with chronic non-

266 traumatic neck pain without dizziness and patients with chronic traumatic neck pain due to

267 whiplash with associated dizziness. The role of reflexes should be compared in patients who

268 suffer from NSCNP with or without associated dizziness for future studies (Ischebeck et al.,

269 2018). In addition, a very relevant aspect in cervical dizziness which was not measured in the 
270 present study is the cervical movement. Some authors consider a hypothesis that goes towards

271 the term "dizziness evoked by cervical movements" would be more appropriate than the current

272 neurophysiological hypothesis of "cervicogenic" dizziness. Cervical dizziness may cause a

273 reduction in cervical mobility in general terms, and specifically, cervical rotation movement

274 (Reid et al., 2014a; L'Heureux-Lebeau et al., 2014; Williams et al., 2017; Grande-Alonso et al., 275 2018a).

276

277 HRQoL

278 EQ-index data showed worse outcomes in patients with combined dizziness and neck pain than

279 in patients with only neck pain. On the other hand, after analyzing the EQ-5D-5L with an

280 individual comparison between domains and levels, we also found worse results for patients with

281 combined dizziness and neck pain than for those with only neck pain. Our results support prior

282 studies addressing HRQoL in patients with NSCNP (Hoy et al., 2014; Vos et al., 2016) in

283 addition to patients with dizziness (Wrisley et al., 2000; Weidt et al., 2014), but our findings add

284 the negative HRQoL effects due to dizziness in conjunction with NSCNP. In addition, neck pain

285 and dizziness are common conditions that frequently appear in patients who attend to primary

286 healthcare services (Gureje et al., 1998; Wipperman, 2014). Thus, dizziness is a persistent

287 condition that may be associated the persistent back pain that is often found in primary care

288 environments (Gureje et al., 1998; Tschan et al., 2013; Wipperman, 2014; Iglebekk, Tjell \&

289 Borenstein, 2017). Consequently, this condition may produce a high economic burden to primary

290 healthcare services (Sun et al., 2014; Mueller et al., 2014; Weidt et al., 2014).

291

292 Disability and fear of movement 
293 The variables of perceived disability in neck pain and kinesiophobia demonstrated worse scores

294 for patients with combined neck pain and dizziness as opposed to those whose only ailment was

295 neck pain. Dizziness may predispose an individual with NSCNP to development of instability

296 and misbalance in addition to an increase in disability levels (Wrisley et al., 2000; Reid \& Rivett,

297 2005; Dickin, 2010; Alahmari et al., 2014; Weidt et al., 2014; Minguez-Zuazo et al., 2016;

298 Grande-Alonso et al., 2018a), which may lead to a higher rate of falls, disability-related

299 problems, and economic burden in primary care patients (Sun et al., 2014; Mueller et al., 2014;

300 Weidt et al., 2014). Therefore, patients who suffered from dizziness associated to NSCNP

301 showed greater fear of movement than patients with isolated NSCNP, which seemed to be in line

302 with prior studies (Dickin, 2010; Alahmari et al., 2014; Minguez-Zuazo et al., 2016; Grande-

303 Alonso et al., 2018a). This fact may be due to dizziness may produce a non-specific anomalous

304 spatial sensation secondary to anomalous spine afferences which may alter visual, vestibular or

305 somatosensory inputs (Minguez-Zuazo et al., 2016).

306 Regarding disability and kinesiophobia of our study, patients with NSCNP without cervicogenic

307 dizziness presented a mean of 55 months of chronicity while patients with dizziness associated to

308 NSCNP showed 43 months suffering from this condition. Despite there were not statistically

309 significant differences between both groups, this fact could suggest greater differences in

310 outcome measurements such as disability and fear of movement. Nevertheless, kinesiophobia

311 scores showed a mean of 24 points in the non-dizziness group while patients with dizziness

312 displayed a mean of 32 points. Regarding chronic pain, the minimum clinically important

313 difference for the TSK-11 was set at 4.8 points and thus the difference of 8 points between both

314 groups may be considered as clinically relevant (Woby et al., 2005; George, Valencia \&

315 Beneciuk, 2010; Hapidou et al., 2012). In addition, the NDI showed mild disability in the non- 
316 dizziness group while patients with dizziness presented moderate disability (Vernon, 2008;

317 Kovacs et al., 2008; MacDermid et al., 2009). The values of the non-dizziness group could be

318 low for disability and fear of movement compared to the chronicity time showed by these

319 patients. Nevertheless, the presence of dizziness could influence a greater impairment of

320 disability and kinesiophobia, even with less time of chronicity, due to a possible wider central

321 sensitization process (Holle et al., 2015).

322

323 Outcome measurements correlations

324 Regarding correlation analyses of our study, all outcome measurements showed statistically

325 significant correlations between them, except for the severity of health quality of life (HRQoL

326 SumScore) and Kinesiophobia (TSK) in the non-dizziness group. Other previous studies have

327 addressed the relationship between HRQoL and psychological outcome measurements associated

328 with pain perpetuation, such as perceived disability and kinesiophobia. According to Kovacs et

329 al, the association between these outcome measurements was analyzed in patients with chronic

330 low back pain showing similar correlation findings in line with our study (Kovacs et al., 2004).

331 As mentioned above, in our study, kinesiophobia was the only outcome measure that did not

332 show any statistically significant correlation with the quality of life severity index in the group of

333 patients without dizziness. This finding could be due to kinesiophobia may be an outcome

334 measure with less influence in subjects with neck pain who did not present associated dizziness.

335 Indeed, kinesiophobia did not present statistically significant correlations with pain intensity or

336 neck disability. Nevertheless, kinesiophobia did seem to be an key outcome measure in those

337 patients with cervicogenic dizziness according to the correlations analysis in the group that

338 presented dizziness and in the same line with previous studies evaluating postural control, 
339 psychological and disability variables in patients with cervicogenic dizziness and neck pain

340 (Grande-Alonso et al., 2018b).

341

\section{Implications for primary care}

343 These results provide a better understanding of the combined effect of these two pathologies,

344 demonstrating the great impact it has on the HRQoL. The area in which this study was conducted

345 was primary care, which is of vital importance since it is the gateway to the public healthcare

346 system in which chronicity and pathology of diseases can best be managed with a correct

347 assessment, referral to specialists, and early intervention (Gureje et al., 1998; Wipperman, 2014).

348 It is important for nurses and clinicians to evaluate all dimensions of the pathology since only by

349 using a biopsychosocial approach can we understand the patient's condition and intervene

350 satisfactorily, thus avoiding the progression of high chronicity with its associated socio-sanitary

351 costs given the high perceived disability that we report in this work (Valenzuela-Pascual et al., 352 2015).

\section{$354 \quad$ Future studies}

355 Due to the reported findings, new interventions should be administered to patients who have 356 combined dizziness and NSCNP in primary care settings in order to increase patients' HRQoL, 357 functionality, and stability. Some treatments such as soft tissue manual therapy (Reid \& Rivett, 358 2005; Reid et al., 2014b), joint mobilization (Reid et al., 2014b), therapeutic patient education, 359 and exercise therapy (Minguez-Zuazo et al., 2016) form a multimodal approach that includes 360 nursing, physical therapy, and other medical specialities. These treatments should be compared 
361 by means of randomized clinical trials in NSCNP patients with dizziness in primary healthcare

362 services.

363

364 Key practice points

365 Greater impairment of HRQoL, functionality, and movement sense were shown in patients with

366 NSCNP combined with dizziness compared to patients with isolated NSCNP. Healthcare actions

367 in research, policy, management and/or education regarding primary care environments for

368 minimizing/preventing HRQoL-associated impairment, disability, and kinesiophobia in patients

369 with NSCNP should be taken, especially when it the NSCNP is combined with dizziness.

370 Physicians and physical therapists can provide these questionnaires to patients with NSCNP and

371 dizziness to detect HRQoL impairment, disability, and kinesiophobia in primary care settings

372 and refer these patients to healthcare management specialists. NSCNP and dizziness

373 management/education in primary care settings should be systematically included in multimodal

374 treatment approaches for patients who suffer from both syndromes.

375

376 Limitations

377 With reference to the study limitations, there may be an inconsistent practice of data

378 transcription. There may also be a limitation with respect to the sample population as patients

379 were recruited from a primary care setting, and although in principle, the results were

380 extrapolated to the entire population given the sample calculation, the conclusion may not be

381 appropriate for certain populations. We also have a high chronicity in both groups within the

382 sample although homogeneity between them is fulfilled. Associated with chronicity is the level

383 of pain severity since one of the inclusion criteria was pain $>3$ on a VAS scale, which is 
384 considered severe/moderate pain. This result was not extrapolated to include patients with mild

385 or no pain. In addition, motion sickness disability was not measured and may be recognized as a

386 main limitation of the present study due to there was not specific outcome measurements related

387 to dizziness. Finally, the present study only evaluated outcome measurements by self-

388 registrations and this may be a limitation due to physical variables, such as cervical range of

389 motion, would be useful in this type of patients in order to study their influence on quality of life

390 and dizziness. Indeed, the TSK-11 total score was the only fear of movement outcome

391 measurement due to this value may be considered as the most relevant index, nevertheless the

392 comparison of the TSK-11 subscales such as Harm and Activity avoidance domains between

393 both groups should be considered for future studies (Roelofs et al., 2004; Gómez-Pérez, López-

394 Martínez \& Ruiz-Párraga, 2011).

395

396 CONCLUSION

397 Patients with NSCNP combined with dizziness present higher HRQoL impairment in addition to

398 higher disability and kinesiophobia compared to patients who only suffer from isolated NSCNP.

400

401

\section{Acknowledgments}

402 The authors did not receive any financial assistance or have any personal relationships with other 403 people or organizations that could inappropriately influence (bias) their work.

404

405

406

407

\section{Disclosure}

The authors report no conflicts of interest in this work.

408 Funding 
409

410

411

412

413

414

415

416

417

418

419

420

421

422

423

424

425

426

427

428

429

430

431

432

433

434

435

436

437

438

439

440

441

442

443

444

445

446

447

448

449

450

451

452

This research was not funded.

\section{REFERENCES}

Alahmari KA, Marchetti GF, Sparto PJ, Furman JM, Whitney SL. 2014. Estimating Postural Control With the Balance Rehabilitation Unit: Measurement Consistency, Accuracy, Validity, and Comparison With Dynamic Posturography. Archives of Physical Medicine and Rehabilitation 95:65-73. DOI: 10.1016/j.apmr.2013.09.011.

Andrade Ortega JA, Delgado Martínez AD, Almécija Ruiz R. 2010. Validation of the Spanish version of the Neck Disability Index. Spine 35:E114-8. DOI:

10.1097/BRS.0b013e3181afea5d.

Argaet EC, Bradshaw AP, Welgampola MS. 2019. Benign positional vertigo, its diagnosis, treatment and mimics. Clinical Neurophysiology Practice 4:97-111. DOI: 10.1016/j.cnp.2019.03.001.

Bijur PE, Silver W, Gallagher EJ. 2001. Reliability of the visual analog scale for measurement of acute pain. Academic emergency medicine : official journal of the Society for Academic Emergency Medicine 8:1153-7.

Bilbao A, García-Pérez L, Arenaza JC, García I, Ariza-Cardiel G, Trujillo-Martín E, Forjaz MJ, Martín-Fernández J. 2018. Psychometric properties of the EQ-5D-5L in patients with hip or knee osteoarthritis: reliability, validity and responsiveness. Quality of Life Research 27:2897-2908. DOI: 10.1007/s11136-018-1929-x.

Coretti S, Ruggeri M, McNamee P. 2014. The minimum clinically important difference for EQ5D index: a critical review. Expert Review of Pharmacoeconomics \& Outcomes Research 14:221-233. DOI: 10.1586/14737167.2014.894462.

Devaraja K. 2018. Approach to cervicogenic dizziness: a comprehensive review of its aetiopathology and management. European Archives of Oto-Rhino-Laryngology 275:24212433. DOI: $10.1007 / \mathrm{s} 00405-018-5088-\mathrm{z}$.

Dickin DC. 2010. Obtaining Reliable Performance Measures on the Sensory Organization Test: Altered Testing Sequences in Young Adults. Clinical Journal of Sport Medicine 20:278285. DOI: 10.1097/JSM.0b013e3181e8f8b1.

von Elm E, Altman DG, Egger M, Pocock SJ, Gøtzsche PC, Vandenbroucke JP, STROBE Initiative. 2007. The Strengthening the Reporting of Observational Studies in Epidemiology (STROBE) statement: guidelines for reporting observational studies. The Lancet 370:14531457. DOI: 10.1016/S0140-6736(07)61602-X.

Falla D, Bilenkij G, Jull G. 2004. Patients with chronic neck pain demonstrate altered patterns of muscle activation during performance of a functional upper limb task. Spine 29:1436-40.

Faul F, Erdfelder E, Lang A-G, Buchner A. 2007. G*Power 3: a flexible statistical power analysis program for the social, behavioral, and biomedical sciences. Behavior research methods 39:175-91.

George SZ, Valencia C, Beneciuk JM. 2010. A psychometric investigation of fear-avoidance model measures in patients with chronic low back pain. The Journal of orthopaedic and sports physical therapy 40:197-205. DOI: 10.2519/jospt.2010.3298.

Gómez-Pérez L, López-Martínez AE, Ruiz-Párraga GT. 2011. Psychometric Properties of the Spanish Version of the Tampa Scale for Kinesiophobia (TSK). The journal of pain : official 
453

454

455

456

457

458

459

460

461

462

463

464

465

466

467

468

469

470

471

472

473

474

475

476

477

478

479

480

481

482

483

484

485

486

487

488

489

490

491

492

493

494

495

496

497

498

journal of the American Pain Society 12:425-35. DOI: 10.1016/j.jpain.2010.08.004.

Grande-Alonso M, Moral Saiz B, Mínguez Zuazo A, Lerma Lara S, La Touche R. 2018a. Biobehavioural analysis of the vestibular system and posture control in patients with cervicogenic dizziness. A cross-sectional study. Neurologia (Barcelona, Spain) 33:98-106. DOI: $10.1016 /$ j.nrl.2016.06.002.

Grande-Alonso M, Moral Saiz B, Mínguez Zuazo A, Lerma Lara S, La Touche R. 2018b. Análisis bioconductual del sistema vestibular y el control postural en pacientes con mareo cervicogénico. Estudio observacional transversal. Neurología 33:98-106. DOI: 10.1016/j.nrl.2016.06.002.

Gureje O, Von Korff M, Simon GE, Gater R. 1998. Persistent Pain and Well-being. JAMA 280:147. DOI: 10.1001/jama.280.2.147.

Hain TC. 2015. Cervicogenic causes of vertigo. Current Opinion in Neurology 28:69-73. DOI: 10.1097/WCO.0000000000000161.

Hapidou EG, O’Brien MA, Pierrynowski MR, de Las Heras E, Patel M, Patla T. 2012. Fear and Avoidance of Movement in People with Chronic Pain: Psychometric Properties of the 11Item Tampa Scale for Kinesiophobia (TSK-11). Physiotherapy Canada. Physiothérapie Canada 64:235-41. DOI: 10.3138/ptc.2011-10.

Hazut N, Medalion S, Kessler DA, Barkai E. 2015. Fractional Edgeworth expansion: Corrections to the Gaussian-Lévy central-limit theorem. Physical review. E, Statistical, nonlinear, and soft matter physics 91:052124.

Herdman M, Gudex C, Lloyd A, Janssen M, Kind P, Parkin D, Bonsel G, Badia X. 2011. Development and preliminary testing of the new five-level version of EQ-5D (EQ-5D-5L). Quality of life research : an international journal of quality of life aspects of treatment, care and rehabilitation 20:1727-36. DOI: 10.1007/s11136-011-9903-X.

Holle D, Schulte-Steinberg B, Wurthmann S, Naegel S, Ayzenberg I, Diener H-C, Katsarava Z, Obermann M. 2015. Persistent Postural-Perceptual Dizziness: A Matter of Higher, Central Dysfunction? PLOS ONE 10:e0142468. DOI: 10.1371/journal.pone.0142468.

Hoy D, March L, Woolf A, Blyth F, Brooks P, Smith E, Vos T, Barendregt J, Blore J, Murray C, Burstein R, Buchbinder R. 2014. The global burden of neck pain: estimates from the global burden of disease 2010 study. Annals of the rheumatic diseases 73:1309-15. DOI: 10.1136/annrheumdis-2013-204431.

Huisstede BMA, Miedema HS, Verhagen AP, Koes BW, Verhaar JAN. 2007. Multidisciplinary consensus on the terminology and classification of complaints of the arm, neck and/or shoulder. Occupational and Environmental Medicine 64:313-319. DOI: 10.1136/oem.2005.023861.

Iglebekk W, Tjell C, Borenstein P. 2017. Pain and other symptoms in patients with chronic benign paroxysmal positional vertigo (BPPV). Scandinavian Journal of Pain 4:233-240. DOI: $10.1016 /$ j.sjpain.2013.06.004.

Ischebeck BK, de Vries J, van Wingerden JP, Kleinrensink GJ, Frens MA, van der Geest JN. 2018. The influence of cervical movement on eye stabilization reflexes: a randomized trial. Experimental Brain Research 236:297-304. DOI: 10.1007/s00221-017-5127-9.

Jensen MP, Karoly P, Braver S. 1986. The measurement of clinical pain intensity: a comparison of six methods. Pain 27:117-26.

Jensen MP, Turner JA, Romano JM, Fisher LD. 1999. Comparative reliability and validity of chronic pain intensity measures. Pain 83:157-62.

Kelley K, Preacher KJ. 2012. On Effect Size. Psychological Methods 17:137-152. DOI:

Peer] reviewing PDF | (2019:05:37989:1:1:NEW 29 Jun 2019) 
499

500

501

502

503

504

505

506

507

508

509

510

511

512

513

514

515

516

517

518

519

520

521

522

523

524

525

526

527

528

529

530

531

532

533

534

535

536

537

538

539

540

541

542

543

544

$10.1037 / \mathrm{a} 0028086$

Kovacs FM, Abraira V, Zamora J, Teresa Gil del Real M, Llobera J, Fernández C, Bauza JR, Bauza K, Coll J, Cuadri M, Duro E, Gili J, Gestoso M, Gómez M, González J, Ibañez P, Jover A, Lázaro P, Llinás M, Mateu C, Mufraggi N, Muriel A, Nicolau C, Olivera MA, Pascual P, Perelló L, Pozo F, Revuelta T, Reyes V, Ribot S, Ripoll J, Ripoll J, Rodríguez E, Kovacs-Atención Primaria Group. 2004. Correlation Between Pain, Disability, and Quality of Life in Patients With Common Low Back Pain. Spine 29:206-210. DOI: 10.1097/01.BRS.0000107235.47465.08.

Kovacs FM, Bagó J, Royuela A, Seco J, Giménez S, Muriel A, Abraira V, Martín JL, Peña JL, Gestoso M, Mufraggi N, Núñez M, Corcoll J, Gómez-Ochoa I, Ramírez MJ, Calvo E, Castillo MD, Martí D, Fuster S, Fernández C, Gimeno N, Carballo A, Milán Á, Vázquez D, Cañellas M, Blanco R, Brieva P, Rueda MT, Álvarez L, del Real MTG, Ayerbe J, González L, Ginel L, Ortega M, Bernal M, Bolado G, Vidal A, Ausín A, Ramón D, Mir MA, Tomás M, Zamora J, Cano A. 2008. Psychometric characteristics of the Spanish version of instruments to measure neck pain disability. BMC Musculoskeletal Disorders 9:42. DOI: 10.1186/1471-2474-9-42.

Kristjansson E, Treleaven J. 2009. Sensorimotor Function and Dizziness in Neck Pain: Implications for Assessment and Management. Journal of Orthopaedic \& Sports Physical Therapy 39:364-377. DOI: 10.2519/jospt.2009.2834.

L'Heureux-Lebeau B, Godbout A, Berbiche D, Saliba I. 2014. Evaluation of Paraclinical Tests in the Diagnosis of Cervicogenic Dizziness. Otology \& Neurotology 35:1858-1865. DOI: 10.1097/MAO.0000000000000506.

MacDermid JC, Walton DM, Avery S, Blanchard A, Etruw E, McAlpine C, Goldsmith CH. 2009. Measurement properties of the neck disability index: a systematic review. The Journal of orthopaedic and sports physical therapy 39:400-17. DOI: 10.2519/jospt.2009.2930.

Matsumoto M, Okada E, Ichihara D, Chiba K, Toyama Y, Fujiwara H, Momoshima S, Nishiwaki Y, Hashimoto T, Inoue T, Watanabe M, Takahata T. 2010. Prospective Ten-Year Follow-up Study Comparing Patients With Whiplash-Associated Disorders and Asymptomatic Subjects Using Magnetic Resonance Imaging. Spine 35:1684-1690. DOI: 10.1097/BRS.0b013e3181c9a8c7.

Minguez-Zuazo A, Grande-Alonso M, Saiz BM, La Touche R, Lara SL. 2016. Therapeutic patient education and exercise therapy in patients with cervicogenic dizziness: a prospective case series clinical study. Journal of exercise rehabilitation 12:216-25. DOI: $10.12965 /$ jer. 1632564.282 .

Mouri H. 2013. Log-normal distribution from a process that is not multiplicative but is additive. Physical review. E, Statistical, nonlinear, and soft matter physics 88:042124.

Mueller M, Strobl R, Jahn K, Linkohr B, Peters A, Grill E. 2014. Burden of disability attributable to vertigo and dizziness in the aged: results from the KORA-Age study. European Journal of Public Health 24:802-807. DOI: 10.1093/eurpub/ckt171.

Obradovic M, Lal A, Liedgens H. 2013. Validity and responsiveness of EuroQol-5 dimension (EQ-5D) versus Short Form-6 dimension (SF-6D) questionnaire in chronic pain. Health and quality of life outcomes 11:110. DOI: 10.1186/1477-7525-11-110.

Oppe M, Devlin NJ, van Hout B, Krabbe PFM, de Charro F. 2014. A program of methodological research to arrive at the new international EQ-5D-5L valuation protocol. Value in health: the journal of the International Society for Pharmacoeconomics and Outcomes Research

Peer) reviewing PDF | (2019:05:37989:1:1:NEW 29 Jun 2019) 
552

553

554

555

556

557

558

559

560

561

562

563

564

565

566

567

568

569

570

571

572

573

574

575

576

577

578

579

580

581

582

583

584

585

586

587

588

589

590

17:445-53. DOI: 10.1016/j.jval.2014.04.002.

Reid SA, Callister R, Katekar MG, Rivett DA. 2014a. Effects of Cervical Spine Manual Therapy on Range of Motion, Head Repositioning, and Balance in Participants With Cervicogenic Dizziness: A Randomized Controlled Trial. Archives of Physical Medicine and Rehabilitation 95:1603-1612. DOI: 10.1016/j.apmr.2014.04.009.

Reid SA, Rivett DA. 2005. Manual therapy treatment of cervicogenic dizziness: a systematic review. Manual Therapy 10:4-13. DOI: 10.1016/j.math.2004.03.006.

Reid SA, Rivett DA, Katekar MG, Callister R. 2014b. Comparison of Mulligan Sustained Natural Apophyseal Glides and Maitland Mobilizations for Treatment of Cervicogenic Dizziness: A Randomized Controlled Trial. Physical Therapy 94:466-476. DOI: 10.2522/ptj.20120483.

Roelofs J, Goubert L, Peters M, Vlaeyen J, Crombez G. 2004. The Tampa scale for kinesiophobia: further examination of psychometric properties in patients with chronic low back pain and fibromyalgia. Eur J Pain 8:495-502.

Sedgwick P. 2012. Pearson's s correlation coefficient. BMJ 4483:1-2. DOI: 10.1136/bmj.e4483.

Setia MS. 2016. Methodology Series Module 2: Case-control Studies. Indian journal of dermatology 61:146-51. DOI: 10.4103/0019-5154.177773.

Sun DQ, Ward BK, Semenov YR, Carey JP, Della Santina CC. 2014. Bilateral Vestibular Deficiency. JAMA Otolaryngology-Head \& Neck Surgery 140:527. DOI: 10.1001/jamaoto.2014.490.

Treleaven J, Jull G, Sterling M. 2003. Dizziness and unsteadiness following whiplash injury: characteristic features and relationship with cervical joint position error. Journal of rehabilitation medicine 35:36-43.

Treleaven J, Peterson G, Ludvigsson ML, Kammerlind A-S, Peolsson A. 2016. Balance, dizziness and proprioception in patients with chronic whiplash associated disorders complaining of dizziness: A prospective randomized study comparing three exercise programs. Manual Therapy 22:122-130. DOI: 10.1016/j.math.2015.10.017.

Tschan R, Best C, Wiltink J, Beutel ME, Dieterich M, Eckhardt-Henn A. 2013. Persistence of Symptoms in Primary Somatoform Vertigo and Dizziness. The Journal of Nervous and Mental Disease 201:328-333. DOI: 10.1097/NMD.0b013e318288e2ad.

Valenzuela-Pascual F, Molina F, Corbi F, Blanco-Blanco J, Gil RM, Soler-Gonzalez J. 2015. The influence of a biopsychosocial educational internet-based intervention on pain, dysfunction, quality of life, and pain cognition in chronic low back pain patients in primary care: a mixed methods approach. BMC Medical Informatics and Decision Making 15:97. DOI: $10.1186 / \mathrm{s} 12911-015-0220-0$.

Vernon H. 2008. The Neck Disability Index: state-of-the-art, 1991-2008. Journal of manipulative and physiological therapeutics 31:491-502. DOI: 10.1016/j.jmpt.2008.08.006.

Vos T, Allen C, Arora M, Barber RM, Bhutta ZA, Brown A, Carter A, Casey DC, Charlson FJ, Chen AZ, Coggeshall M, Cornaby L, Dandona L, Dicker DJ, Dilegge T, Erskine HE, Ferrari AJ, Fitzmaurice C, Fleming T, Forouzanfar MH, Fullman N, Gething PW, Goldberg EM, Graetz N, Haagsma JA, Hay SI, Johnson CO, Kassebaum NJ, Kawashima T, Kemmer L, Khalil IA, Kinfu Y, Kyu HH, Leung J, Liang X, Lim SS, Lopez AD, Lozano R, Marczak L, Mensah GA, Mokdad AH, Naghavi M, Nguyen G, Nsoesie E, Olsen H, Pigott DM, Pinho C, Rankin Z, Reinig N, Salomon JA, Sandar L, Smith A, Stanaway J, Steiner C, Teeple S, Thomas BA, Troeger C, Wagner JA, Wang H, Wanga V, Whiteford HA, 
591

592

593

594

595

596

597

598

599

600

601

602

603

604

605

606

607

608

609

610

611

612

613

614

615

616

617

618

619

620

621

622

623

624

625

626

627

628

629

630

631

632

633

634

635

636
Zoeckler L, Abajobir AA, Abate KH, Abbafati C, Abbas KM, Abd-Allah F, Abraham B, Abubakar I, Abu-Raddad LJ, Abu-Rmeileh NME, Ackerman IN, Adebiyi AO, Ademi Z, Adou AK, Afanvi KA, Agardh EE, Agarwal A, Kiadaliri AA, Ahmadieh H, Ajala ON, Akinyemi RO, Akseer N, Al-Aly Z, Alam K, Alam NKM, Aldhahri SF, Alegretti MA, Alemu ZA, Alexander LT, Alhabib S, Ali R, Alkerwi A, Alla F, Allebeck P, Al-Raddadi R, Alsharif U, Altirkawi KA, Alvis-Guzman N, Amare AT, Amberbir A, Amini H, Ammar W, Amrock SM, Andersen HH, Anderson GM, Anderson BO, Antonio CAT, Aregay AF, Ärnlöv J, Artaman A, Asayesh H, Assadi R, Atique S, Avokpaho EFGA, Awasthi A, Quintanilla BPA, Azzopardi P, Bacha U, Badawi A, Balakrishnan K, Banerjee A, Barac A, Barker-Collo SL, Bärnighausen T, Barregard L, Barrero LH, Basu A, Bazargan-Hejazi S, Beghi E, Bell B, Bell ML, Bennett DA, Bensenor IM, Benzian H, Berhane A, Bernabé E, Betsu BD, Beyene AS, Bhala N, Bhatt S, Biadgilign S, Bienhoff K, Bikbov B, Biryukov S, Bisanzio D, Bjertness E, Blore J, Borschmann R, Boufous S, Brainin M, Brazinova A, Breitborde NJK, Brown J, Buchbinder R, Buckle GC, Butt ZA, Calabria B, Campos-Nonato IR, Campuzano JC, Carabin H, Cárdenas R, Carpenter DO, Carrero JJ, Castañeda-Orjuela CA, Rivas JC, Catalá-López F, Chang J-C, Chiang PP-C, Chibueze CE, Chisumpa VH, Choi J-YJ, Chowdhury R, Christensen H, Christopher DJ, Ciobanu LG, Cirillo M, Coates MM, Colquhoun SM, Cooper C, Cortinovis M, Crump JA, Damtew SA, Dandona R, Daoud F, Dargan PI, das Neves J, Davey G, Davis AC, Leo D De, Degenhardt L, Gobbo LC Del, Dellavalle RP, Deribe K, Deribew A, Derrett S, Jarlais DC Des, Dharmaratne SD, Dhillon PK, Diaz-Torné C, Ding EL, Driscoll TR, Duan L, Dubey M, Duncan BB, Ebrahimi H, Ellenbogen RG, Elyazar I, Endres M, Endries AY, Ermakov SP, Eshrati B, Estep K, Farid TA, Farinha CS e S, Faro A, Farvid MS, Farzadfar F, Feigin VL, Felson DT, Fereshtehnejad S-M, Fernandes JG, Fernandes JC, Fischer F, Fitchett JRA, Foreman K, Fowkes FGR, Fox J, Franklin RC, Friedman J, Frostad J, Fürst T, Futran ND, Gabbe B, Ganguly P, Gankpé FG, Gebre T, Gebrehiwot TT, Gebremedhin AT, Geleijnse JM, Gessner BD, Gibney KB, Ginawi IAM, Giref AZ, Giroud M, Gishu MD, Giussani G, Glaser E, Godwin WW, Gomez-Dantes H, Gona P, Goodridge A, Gopalani SV, Gotay CC, Goto A, Gouda HN, Grainger R, Greaves F, Guillemin F, Guo Y, Gupta R, Gupta R, Gupta V, Gutiérrez RA, Haile D, Hailu AD, Hailu GB, Halasa YA, Hamadeh RR, Hamidi S, Hammami M, Hancock J, Handal AJ, Hankey GJ, Hao Y, Harb HL, Harikrishnan S, Haro JM, Havmoeller R, Hay RJ, Heredia-Pi IB, Heydarpour P, Hoek HW, Horino M, Horita N, Hosgood HD, Hoy DG, Htet AS, Huang H, Huang JJ, Huynh C, Iannarone M, Iburg KM, Innos K, Inoue M, Iyer VJ, Jacobsen KH, Jahanmehr N, Jakovljevic MB, Javanbakht M, Jayaraman SP, Jayatilleke AU, Jee SH, Jeemon P, Jensen PN, Jiang Y, Jibat T, JimenezCorona A, Jin Y, Jonas JB, Kabir Z, Kalkonde Y, Kamal R, Kan H, Karch A, Karema CK, Karimkhani C, Kasaeian A, Kaul A, Kawakami N, Keiyoro PN, Kemp AH, Keren A, Kesavachandran CN, Khader YS, Khan AR, Khan EA, Khang Y-H, Khera S, Khoja TAM, Khubchandani J, Kieling C, Kim P, Kim C, Kim D, Kim YJ, Kissoon N, Knibbs LD, Knudsen AK, Kokubo Y, Kolte D, Kopec JA, Kosen S, Kotsakis GA, Koul PA, Koyanagi A, Kravchenko M, Defo BK, Bicer BK, Kudom AA, Kuipers EJ, Kumar GA, Kutz M, Kwan GF, Lal A, Lalloo R, Lallukka T, Lam H, Lam JO, Langan SM, Larsson A, Lavados PM, Leasher JL, Leigh J, Leung R, Levi M, Li Y, Li Y, Liang J, Liu S, Liu Y, Lloyd BK, Lo WD, Logroscino G, Looker KJ, Lotufo PA, Lunevicius R, Lyons RA, Mackay MT, Magdy M, Razek A El, Mahdavi M, Majdan M, Majeed A, Malekzadeh R, Marcenes W, Margolis DJ, Martinez-Raga J, Masiye F, Massano J, McGarvey ST, McGrath JJ, McKee 
637

638

639

640

641

642

643

644

645

646

647

648

649

650

651

652

653

654

655

656

657

658

659

660

661

662

663

664

665

666

667

668

669

670

671

672

673

674

675

676

677

678

679

680

681

682
M, McMahon BJ, Meaney PA, Mehari A, Mejia-Rodriguez F, Mekonnen AB, Melaku YA, Memiah P, Memish ZA, Mendoza W, Meretoja A, Meretoja TJ, Mhimbira FA, Millear A, Miller TR, Mills EJ, Mirarefin M, Mitchell PB, Mock CN, Mohammadi A, Mohammed S, Monasta L, Hernandez JCM, Montico M, Mooney MD, Moradi-Lakeh M, Morawska L, Mueller UO, Mullany E, Mumford JE, Murdoch ME, Nachega JB, Nagel G, Naheed A, Naldi L, Nangia V, Newton JN, Ng M, Ngalesoni FN, Nguyen Q Le, Nisar MI, Pete PMN, Nolla JM, Norheim OF, Norman RE, Norrving B, Nunes BP, Ogbo FA, Oh I-H, Ohkubo T, Olivares PR, Olusanya BO, Olusanya JO, Ortiz A, Osman M, Ota E, PA M, Park E-K, Parsaeian M, de Azeredo Passos VM, Caicedo AJP, Patten SB, Patton GC, Pereira DM, Perez-Padilla R, Perico N, Pesudovs K, Petzold M, Phillips MR, Piel FB, Pillay JD, Pishgar F, Plass D, Platts-Mills JA, Polinder S, Pond CD, Popova S, Poulton RG, Pourmalek F, Prabhakaran D, Prasad NM, Qorbani M, Rabiee RHS, Radfar A, Rafay A, Rahimi K, Rahimi-Movaghar V, Rahman M, Rahman MHU, Rahman SU, Rai RK, Rajsic S, Ram U, Rao P, Refaat AH, Reitsma MB, Remuzzi G, Resnikoff S, Reynolds A, Ribeiro AL, Blancas MJR, Roba HS, Rojas-Rueda D, Ronfani L, Roshandel G, Roth GA, Rothenbacher D, Roy A, Sagar R, Sahathevan R, Sanabria JR, Sanchez-Niño MD, Santos IS, Santos JV, Sarmiento-Suarez R, Sartorius B, Satpathy M, Savic M, Sawhney M, Schaub MP, Schmidt MI, Schneider IJC, Schöttker B, Schwebel DC, Scott JG, Seedat S, Sepanlou SG, ServanMori EE, Shackelford KA, Shaheen A, Shaikh MA, Sharma R, Sharma U, Shen J, Shepard DS, Sheth KN, Shibuya K, Shin M-J, Shiri R, Shiue I, Shrime MG, Sigfusdottir ID, Silva DAS, Silveira DGA, Singh A, Singh JA, Singh OP, Singh PK, Sivonda A, Skirbekk V, Skogen JC, Sligar A, Sliwa K, Soljak M, Søreide K, Sorensen RJD, Soriano JB, Sposato LA, Sreeramareddy CT, Stathopoulou V, Steel N, Stein DJ, Steiner TJ, Steinke S, Stovner L, Stroumpoulis K, Sunguya BF, Sur P, Swaminathan S, Sykes BL, Szoeke CEI, TabarésSeisdedos R, Takala JS, Tandon N, Tanne D, Tavakkoli M, Taye B, Taylor HR, Ao BJ Te, Tedla BA, Terkawi AS, Thomson AJ, Thorne-Lyman AL, Thrift AG, Thurston GD, TobeGai R, Tonelli M, Topor-Madry R, Topouzis F, Tran BX, Truelsen T, Dimbuene ZT, Tsilimbaris M, Tura AK, Tuzcu EM, Tyrovolas S, Ukwaja KN, Undurraga EA, Uneke CJ, Uthman OA, van Gool CH, Varakin YY, Vasankari T, Venketasubramanian N, Verma RK, Violante FS, Vladimirov SK, Vlassov VV, Vollset SE, Wagner GR, Waller SG, Wang L, Watkins DA, Weichenthal S, Weiderpass E, Weintraub RG, Werdecker A, Westerman R, White RA, Williams HC, Wiysonge CS, Wolfe CDA, Won S, Woodbrook R, Wubshet M, Xavier D, Xu G, Yadav AK, Yan LL, Yano Y, Yaseri M, Ye P, Yebyo HG, Yip P, Yonemoto N, Yoon S-J, Younis MZ, Yu C, Zaidi Z, Zaki MES, Zeeb H, Zhou M, Zodpey S, Zuhlke LJ, Murray CJL. 2016. Global, regional, and national incidence, prevalence, and years lived with disability for 310 diseases and injuries, 1990-2015: a systematic analysis for the Global Burden of Disease Study 2015. The Lancet 388:1545-1602. DOI: 10.1016/S0140-6736(16)31678-6.

Weidt S, Bruehl AB, Straumann D, Hegemann SC, Krautstrunk G, Rufer M. 2014. Healthrelated quality of life and emotional distress in patients with dizziness: a cross-sectional approach to disentangle their relationship. BMC Health Services Research 14:317. DOI: 10.1186/1472-6963-14-317.

Williams G, Sarig-Bahat H, Williams K, Tyrrell R, Treleaven J. 2017. Cervical kinematics in patients with vestibular pathology vs. patients with neck pain: A pilot study. Journal of Vestibular Research 27:137-145. DOI: 10.3233/VES-170615.

Wipperman J. 2014. Dizziness and Vertigo. Primary Care: Clinics in Office Practice 41:115- 
683 131. DOI: 10.1016/j.pop.2013.10.004.

684 Woby SR, Roach NK, Urmston M, Watson PJ. 2005. Psychometric properties of the TSK-11: A 685 shortened version of the Tampa Scale for Kinesiophobia. Pain 117:137-144. DOI:

$686 \quad$ 10.1016/j.pain.2005.05.029.

687 Wrisley DM, Sparto PJ, Whitney SL, Furman JM. 2000. Cervicogenic Dizziness: A Review of 688 Diagnosis and Treatment. Journal of Orthopaedic \& Sports Physical Therapy 30:755-766. 689 DOI: $10.2519 /$ jospt.2000.30.12.755.

690

691 


\section{Table $\mathbf{1}$ (on next page)}

Table 1

Table 1. Description and comparison of quantitative sociodemographic variables for the Dizziness and Non-Dizziness NSCNP groups 
1

Table 1. Description and comparison of quantitative sociodemographic variables for the Dizziness and Non-Dizziness NSCNP groups

\begin{tabular}{|c|c|c|c|c|c|c|}
\hline & \multirow{2}{*}{$\begin{array}{l}\text { Dizziness } \\
(\mathrm{n}=60) \\
\text { Mean } \pm \mathrm{SD}\end{array}$} & \multirow{2}{*}{$\begin{array}{c}\text { Non Dizziness } \\
\qquad(\mathrm{n}=60) \\
\text { Mean } \pm \mathrm{SD}\end{array}$} & \multirow{2}{*}{$\begin{array}{l}\text { Mean } \\
\text { Dif. }\end{array}$} & \multicolumn{2}{|c|}{ IC 95\% de la Dif. } & \multirow{2}{*}{$\begin{array}{l}\text { Effect Size } \\
\text { (Cohen's } d \text { ) }\end{array}$} \\
\hline & & & & Inferior & - Superior & \\
\hline Age (years) & $51.27 \pm 11.75$ & $47.53 \pm 13.36$ & 3.73 & -0.82 & 8.28 & $d=0.30$ \\
\hline BMI & $25.66 \pm 3.86$ & $24.77 \pm 4.07$ & 0.88 & -0.55 & 2.32 & $d=0.23$ \\
\hline Chronicity Time (months) & $43.51 \pm 59.56$ & $55.02 \pm 67.07$ & -11.50 & -34.44 & 11.42 & $d=-0.18$ \\
\hline Pain Intensity (VAS) & $63.00 \pm 15.85$ & $58.35 \pm 19.67$ & 4.65 & -1.81 & 11.11 & $d=0.26$ \\
\hline
\end{tabular}

SD. Standard Deviation; CI. Confident Interval; BMI. Body Mass Index; VAS. Visual Analogue Scale

2

3

4

5

6

7

8

9

10

11

12

13

14

15

16

17

18 


\section{Table 2 (on next page)}

Table 2

Table 2. Description of qualitative sociodemographic variables between Dizziness and NonDizziness NSCNP groups 
Table 2. Description of qualitative sociodemographic variables between

Dizziness and Non-Dizziness NSCNP groups

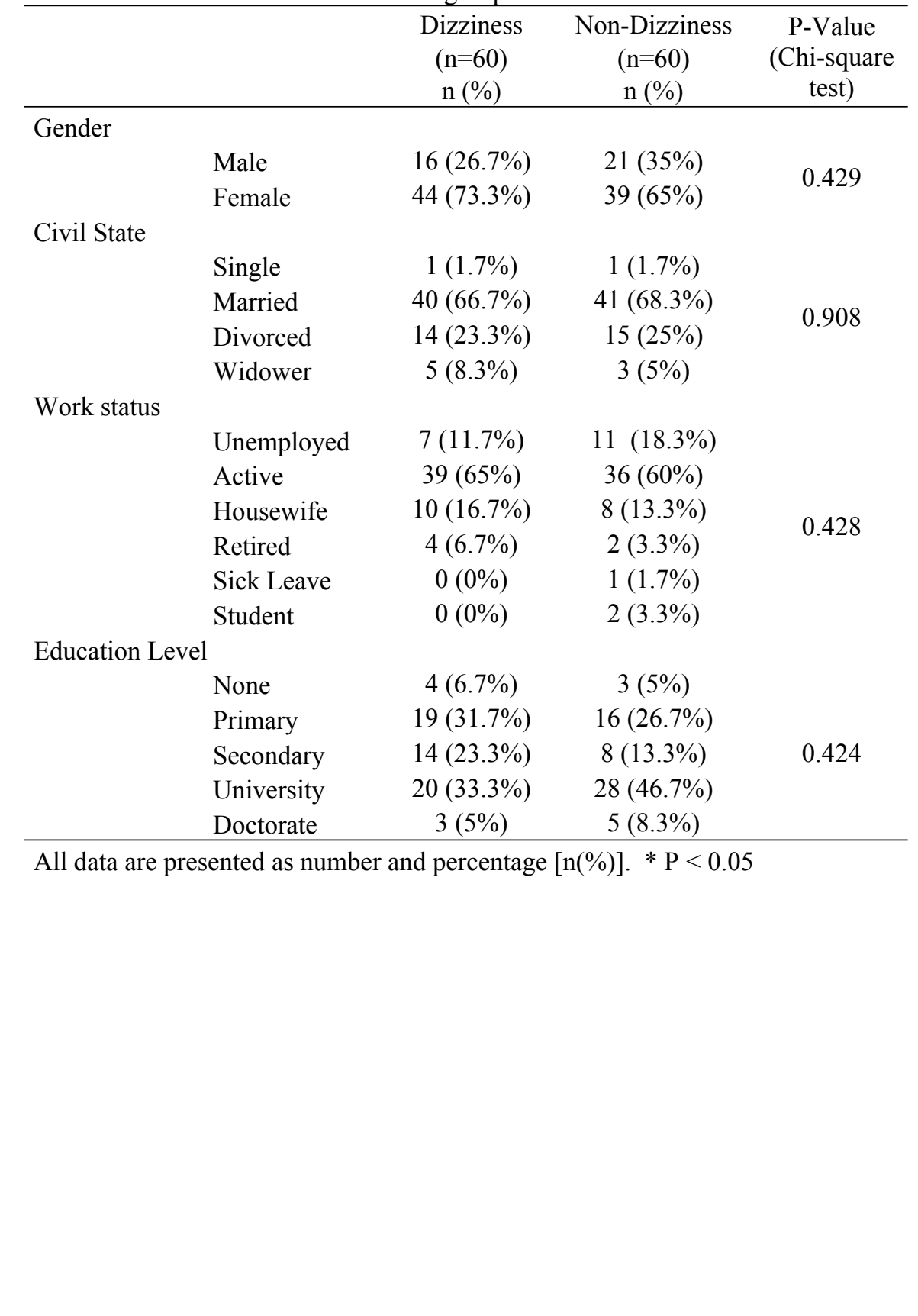




\section{Table 3(on next page)}

Table 3

Table 3. Descriptive data and of five dimensions of EQ-5D and comparison between the Dizziness and Non-Dizziness patients with NSCNP 
Table 3. Descriptive data and of five dimensions of EQ-5D and comparison between the Dizziness and Non-Dizziness patients with NSCNP

\begin{tabular}{|c|c|c|c|c|}
\hline \multirow{2}{*}{\multicolumn{2}{|c|}{ EQ-5D DIMENSION \& LEVELS }} & \multicolumn{2}{|c|}{ GROUPS } & \multirow{2}{*}{ P-Value } \\
\hline & & $\begin{array}{c}\text { Dizziness } \\
(n=60)\end{array}$ & \begin{tabular}{|c|} 
Non-Dizziness \\
$(n=60)$ \\
\end{tabular} & \\
\hline \multirow{5}{*}{ MOBILITY } & No Problem & $28(46.7 \%)$ & $47(78.3 \%)$ & \multirow{5}{*}{0.003} \\
\hline & Slight Problem & $19(31.7 \%)$ & $8(13.3 \%)$ & \\
\hline & Moderate Problem & $10(16.7 \%)$ & $5(8.3 \%)$ & \\
\hline & Severe Proble & $3(5 \%)$ & $0(0 \%)$ & \\
\hline & Unable to & $0(0 \%)$ & $0(0 \%)$ & \\
\hline \multirow{5}{*}{ SELF-CARE } & No Problem & $30(50 \%)$ & $49(81.7 \%)$ & \multirow{5}{*}{0.003} \\
\hline & Slight Problem & $18(30 \%)$ & $6(10 \%)$ & \\
\hline & Moderate Problem & $11(18.3 \%)$ & $5(8.3 \%)$ & \\
\hline & Severe Proble & $1(1.7 \%)$ & $0(0 \%)$ & \\
\hline & Unable to & $0(0 \%)$ & $0(0 \%)$ & \\
\hline \multirow{5}{*}{ USUAL ACTIVITIES } & No Problem & $6(10 \%)$ & $30(50 \%)$ & \multirow{5}{*}{$<0.001$} \\
\hline & Slight Problem & $24(40 \%)$ & $17(28.3 \%)$ & \\
\hline & Moderate Problem & $25(41.7 \%)$ & $13(21.7 \%)$ & \\
\hline & Severe Proble & $4(6.7 \%)$ & $0(0 \%)$ & \\
\hline & Unable to & $1(1.7 \%)$ & $0(0 \%)$ & \\
\hline \multirow{5}{*}{ PAIN / DISCOMFORT } & No Problem & $0(0 \%)$ & $6(10 \%)$ & \multirow{5}{*}{$<0.001$} \\
\hline & Slight Problem & $9(15 \%)$ & $22(36.7 \%)$ & \\
\hline & Moderate Problem & $30(50 \%)$ & $26(43.3 \%)$ & \\
\hline & Severe Proble & $19(31.7 \%)$ & $6(10 \%)$ & \\
\hline & Unable to & $2(3.3 \%)$ & $0(0 \%)$ & \\
\hline \multirow{5}{*}{ ANXIETY / DEPRESSION } & No Problem & $14(23.3 \%)$ & $32(53.3 \%)$ & \multirow{5}{*}{0.004} \\
\hline & Slight Problem & $17(28.3 \%)$ & $15(25 \%)$ & \\
\hline & Moderate Problem & $14(23.3 \%)$ & $9(15 \%)$ & \\
\hline & Severe Proble & $12(20 \%)$ & $4(6.7 \%)$ & \\
\hline & Unable to & $3(5 \%)$ & $0(0 \%)$ & \\
\hline
\end{tabular}

All data are presented as number and percentage [n(\%)]. NSCNP. Non-Specific Chronic Neck Pain; EQ5D. EuroQoL Five Dimensions 
Table 4 (on next page)

Table 4

Table 4. Comparison of quantitative variables for the Dizziness and Non-Dizziness groups in patients with NSCNP 
Table 4. Comparison of quantitative variables for the Dizziness and Non-Dizziness groups in patients with NSCNP

\begin{tabular}{|c|c|c|c|c|c|c|}
\hline & \multirow{2}{*}{$\begin{array}{c}\text { Dizziness } \\
(\mathrm{n}=60) \\
\text { Mean } \pm \text { SD }\end{array}$} & \multirow{2}{*}{$\begin{array}{l}\text { Non-Dizziness } \\
\qquad(\mathrm{n}=60) \\
\text { Mean } \pm \text { SD }\end{array}$} & \multirow{2}{*}{$\begin{array}{l}\text { Mean } \\
\text { Dif. }\end{array}$} & \multicolumn{2}{|c|}{$95 \%$ of $\mathrm{CI}$} & \multirow{2}{*}{$\begin{array}{l}\text { Effect Size } \\
\text { (Cohen's } d)\end{array}$} \\
\hline & & & & Inferior & - Superior & \\
\hline HRQoL Sum Score & $34 \pm 14.34$ & $17.83 \pm 13.69$ & 16.16 & 11.09 & 21.23 & $d=1.16^{*}$ \\
\hline EQ VAS & $55.25 \pm 17.76$ & $67.97 \pm 19.77$ & -12.71 & -19.51 & -5.92 & $d=-0.68^{*}$ \\
\hline NDI & $19.08 \pm 7.55$ & $12.78 \pm 5.91$ & 6.30 & 3.84 & 8.75 & $d=0.94 *$ \\
\hline TSK-11 & $32.40 \pm 6.56$ & $24.03 \pm 6.10$ & 8.36 & 6.07 & 10.65 & $d=1.33^{*}$ \\
\hline
\end{tabular}

NSCNP. Non-Specific Chronic Neck Pain; SD. Standard Deviation; CI. Confident Interval;

VAS.Visual Analogue Scale; HRQoL. Health Related Quality of Life; EQ VAS. EuroQoL Visual

Analogue Scale; NDI. Neck Disability Index; TSK-11. Tampa Scale of Kinesiophobia; * P $<0.05$

4

5

6

7

8

9

10

11

12

13

14

15

16

17

18

19

20

21

22 


\section{Table 5 (on next page)}

Pearson's correlations with continuous variables in the dizziness group.

HRQoL = Health Related Quality of Life; NDI = Neck Disability Index; TSK = Tampa Scale of Kinesiophobia; VAS-EQ = Visual Analogue Scale from EuroQoL-5D-5L * The correlation is statistically significant at an alpha level of 0.05 (2 tails). ** The correlation is statistically significant at an alpha level of 0.01 (2 tails). 
Table 5. Pearson's correlations with continuous variables in the dizziness group.

\begin{tabular}{lccccc} 
& Pain Intensity & NDI & TSK & VAS-EQ & HRQoL SumScore \\
Pain Intensity & 1 & $0.352^{* *}$ & $0.278^{*}$ & $-0.558^{* *}$ & $0.451^{* *}$ \\
NDI & $0.352^{* *}$ & 1 & $0.526^{* *}$ & $-0.558^{* *}$ & $0.649^{* *}$ \\
TSK & $0.278^{*}$ & $0.526^{* *}$ & 1 & $-0.479^{* *}$ & $0.471^{* *}$ \\
VAS EuroQoL & $-0.558^{* *}$ & $-0.558^{* *}$ & $-0.479^{* *}$ & 1 & $-0.679^{* *}$ \\
HRQoL SumScore & $0.451^{* *}$ & $0.649^{* *}$ & $0.471^{* *}$ & $-0.679^{* *}$ & 1 \\
\hline
\end{tabular}

HRQoL $=$ Health Related Quality of Life; NDI = Neck Disability Index; TSK = Tampa Scale of Kinesiophobia; VAS-EQ $=$ Visual Analogue Scale from EuroQoL-5D-5L

* The correlation is statistically significant at an alpha level of 0.05 (2 tails).

** The correlation is statistically significant at an alpha level of 0.01 (2 tails). 


\section{Table 6(on next page)}

Pearson's Correlations with continuous variables in non-dizziness group.

HRQoL = Health Related Quality of Life; NDI = Neck Disability Index; TSK = Tampa Scale of Kinesiophobia; VAS-EQ = Visual Analogue Scale from EuroQoL-5D-5L * The correlation is statistically significant at an alpha level of 0.05 (2 tails). ** The correlation is statistically significant at an alpha level of 0.01 (2 tails). 
Table 6. Pearson's Correlations with continuous variables in non-dizziness group.

\begin{tabular}{|c|c|c|c|c|c|}
\hline & Pain Intensity & NDI & TSK & VAS EuroQoL & HRQoL SumScore \\
\hline Pain Intensity & 1 & $0.340 * *$ & 0.112 & -0.225 & $0.325^{*}$ \\
\hline NDI & $0.340 * *$ & 1 & 0.147 & $-0.527 * *$ & $0.725 * *$ \\
\hline TSK & 0.112 & 0.147 & 1 & $-0.301 *$ & 0.249 \\
\hline VAS-EQ & -0.225 & $-0.527 * *$ & $-0.301 *$ & 1 & $-0.558 * *$ \\
\hline HRQoL SumScore & $0.325 *$ & $0.725^{* *}$ & 0.249 & $-0.558 * *$ & 1 \\
\hline
\end{tabular}

